\title{
NOCIONES Y CRITERIOS DE LA CIUDAD ACCESIBLE Movilidad peatonal en intersección vial de la carrera 17 en Bogotá
}

\author{
Autora: Jennifer Cañaveral Guzmán. \\ Universidad Nacional de Colombia. \\ Directora de la tesis: Mónica Sánchez \\ Co-Directora de tesis: Tatiana Urrea \\ Email: ijcanaveralg@unal.edu.co
}

\section{RESUMEN}

El plan a desarrollar en este documento es "Nociones y criterios de la ciudad accesible", cuyo objetivo es analizar y ordenar la accesibilidad urbanística y formular una política pública para la ciudad accesible adecuada a las necesidades de las personas con diferentes discapacidades. Esta investigación se enfoca en el estudio de las problemáticas urbanas de dos localidades en Bogotá, Teusaquillo y Barrios Unidos, delimitados entre la carrera 17 desde la calle 57 , hasta la calle 67 , y en la generación de propuestas orientadas a la mejora de la movilidad para las personas en condición de discapacidad, contribuyendo a mejorar las condiciones de movilidad del sector para tener una excelente calidad de vida de la población con discapacidades, que apoyan en las entidades públicas y gobiernos. Mejorar del transporte público y la creación de nuevos espacios verdes en la ciudad hacia un nuevo modelo urbanístico sostenible e integral.

Palabras claves: Movilidad peatonal, accesibilidad, inclusión social.

\begin{abstract}
The plan to be developed in this document is "Notions and criteria of the accessible city", whose objective is to analyze and order urban accessibility and formulate a public policy for the city accessible to the needs of people with different disabilities. This research focuses on the study of the urban problems of two localities in Bogotá, Teusaquillo and Barrios Unidos, delimited between race 17 from street 57 to street 67, and the generation of proposals aimed at improving mobility for people in Condition of disability, will help improve the mobility conditions of the sector to have an excellent quality of life for the population with disabilities, who support in public entities and governments. Improve public transportation and the creation of new green spaces in the city towards a new sustainable and integral urban model.
\end{abstract}

Key words: Pedestrian mobility, accessibility, social inclusion. 


\section{INTRODUCCIÓN}

La evolución de la ciudad y su historia a través de accesibilidad ha generado dos instancias en términos urbanos: lo privado y lo público. Los espacios privados son aquellos lugares delimitados o predios donde se desarrollan las actividades privadas y los espacios públicos, son aquellos sitios de congregación y circulación de personas, entre los cuales se encuentran los espacios públicos peatonales, hitos, nodos y modos de transportes, etc., generando en la movilidad peatonal espacios de agrupación y lugares de conexión.

Uno de los conceptos guiados en este documento es el proyecto de ciudad accesible representado para la investigación de diferentes zonas de intervención peatonal, generadas por las características del lugar como referentes urbanos que se articula en la carrera 17 en dos localidades: Teusaquillo y Barrios Unidos.

Es muy complejo encontrar una definición que abarque todo el concepto de ciudad accesible, pues erróneamente se ha pensado en que éste solamente aplica para personas en condición de discapacidad. No obstante, la ciudad accesible abarca mucho más; debe incluir la movilidad de todos, contemplar los criterios de accesibilidad de forma transversal en todas las disciplinas, deben tener la calidad que no tengan las críticas de la ciudad accesible. Como lo señala Corbalán: "No es fácil definir lo que es una ciudad accesible, porque la accesibilidad toca numerosas disciplinas que hacen muy difícil redactar una definición empleando palabras. Sin embargo, sí que podemos decir que una ciudad accesible se puede detectar por la experiencia de cualquier ciudadano en su día a día dentro de una ciudad. Cuanta mejor sea la experiencia, mayor será el grado de accesibilidad que la ciudad ofrece y no sólo por personas con discapacidad, aquí entramos todos en el mismo saco" (Antonio Corbalán, 2014).

Comúnmente se piensa que la solución es únicamente la implementación de rampas o vados, sin embargo, debe ser mucho más que el diseño del andén; por lo tanto, es importante tener clara la definición de ciudad accesible para todos.

Como parte fundamental de este componente y de acuerdo con la Ley 1618 de $2013^{1}$, cada una de las zonas que se contemplen como espacios públicos dentro de un proyecto, tales como andenes, vados y cruces peatonales a nivel, deberán cumplir con los parámetros establecidos en las normas técnicas y manuales de accesibilidad, movilidad reducida y decretos distritales. Alejandra Forlán, Fundadora, Psicóloga, Conferencista y Activista uruguaya habló en una entrevista: "[...] ojalá algún día haya más trabajo para las personas con alguna discapacidad. También se podría mejorar la ciudad. Hay muchas veredas rotas, faltan rampas y, entre otras cosas, nos es difícil ir al supermercado porque no podemos pasar por las cajas a pagar. Faltan taxis accesibles y ómnibus de todas las líneas para nosotros"). Para Forlán lo importante es generar empatía: "[...] La mejor manera de entender la falta de accesibilidad es ponerse en el lugar de quien tiene una discapacidad" Forlàn, 2012).

Este proyecto pretende analizar la accesibilidad en las localidades de Teusaquillo y Barrios Unidos, teniendo en cuenta los parámetros establecidos en las Fichas de Accesibilidad y la Cartilla de Andenes (Instituto de Desarrollo Urbano y Secretaria Distrital de Planeación de Bogotá) para evaluar si cumplen o no la normativa de accesibilidad. La zona seleccionada para este estudio se ubica en la carrera 17 entre la calle 57 hasta la calle 67, donde se analizan: andenes, rampas, vados, cruces peatonales, intersecciones viales, accesos al transporte público, mobiliario urbano, zonas verdes y señalización. Adicionalmente, se espera hacer un llamado de atención a quienes intervienen en las decisiones relacionadas con la accesibilidad a los entornos, edificios, servicios y productos, recogiendo las deficiencias encontradas, proponiendo una transformación que permita que se haga efectivo el derecho a la igualdad de oportunidades de las personas con discapacidad en la ciudad.

Una ciudad que no cumpla con las normas de accesibilidad, es una ciudad que carece de continuidad en sus pasos peatonales, lo que genera problemas de andenes y discriminación de los ciudadanos. Diferentes arquitectos se han dedicado a trabajar en proyectos urbanísticos. Tal es el caso de Enrique Rovira, profesor de la Universidad Internacional de Cataluña, quien ha trabajado en dichos proyectos, particularmente en ciudades de España, basándose en el diseño universal. Rovira explica que la ciudad que se piensa universalmente, es una ciudad que les da espacios a todos, sus calles, sus andenes y los materiales.

\section{PLANTEAMIENTO DEL PROBLEMA}

\footnotetext{
${ }^{1}$ Ley 1618 de 2013 "por medio de la cual se establecen las disposiciones para garantizar el pleno ejercicio de los derechos de las personas con discapacidad", Artículo 14: Acceso y Accesibilidad. Congreso de Colombia. (2013:13).
} 


\subsection{Antecedentes.}

La ciudad es paradigma de los problemas del crecimiento urbano, con su gravitante componente de extra legalidad de la ocupación territorial para dar las oportunidades de los usuarios para avanzar hacia las debidas condiciones de accesibilidad para todas las personas: alcanzar una accesibilidad urbana universal.

En gran medida y en todas las ciudades, se advierten una variedad de barreras urbanísticas que van en aumento, que limitan la circulación eficiente y segura de las personas, y en ciertos casos, que anulan las posibilidades de accesibilidad urbana a las personas con discapacidad. Pero ¿qué define ese derecho a la ciudad? El derecho a la ciudad no es el simplemente el derecho a lo que ya existe. En la Nueva Agenda Urbana quedó incorporado el Derecho a la Ciudad en el párrafo 11, el cual señala que: "Compartimos el ideal de una ciudad para todos, refiriéndonos a la igualdad en el uso y el disfrute de las ciudades y los asentamientos humanos y buscando promover la inclusividad y garantizar que todos los habitantes, tanto de las generaciones presentes como futuras, sin discriminación de ningún tipo, puedan crear ciudades y asentamientos humanos justos, seguros, sanos, accesibles, asequibles, resilientes y sostenibles y habitar en ellos, a fin de promover la prosperidad y la calidad de vida para todos. Hacemos notar los esfuerzos de algunos gobiernos nacionales y locales para consagrar este ideal, conocido como "el derecho a la ciudad", en sus leyes, declaraciones políticas y cartas" (2016:04). La resolución fue aprobada por la Asamblea General el 23 de diciembre de 2016. ${ }^{2}$ No se trata de querer acceder al estado de cosa actual, o sea a lo que los especuladores de la propiedad y los funcionarios estatales han decidido fragmentariamente, sino el derecho activo a hacer una ciudad diferente. Imaginar una ciudad más accesible, aunque siempre conflictiva, basada no sólo en una diferente jerarquización de los derechos, sino también en diferentes prácticas políticas, sociales y económicas. Si nuestro mundo urbano ha sido imaginado y luego hecho, puede ser re-imaginado y re-hecho. El inalienable derecho a la ciudad es algo por lo que vale la pena luchar.

En términos generales, Bogotá no cumple con las normas de accesibilidad aplicadas y políticas públicas para mejorarla y hacerla una ciudad accesible. La norma técnica colombiana 6047 de ICONTEC sobre Accesibilidad Física, es de estricto cumplimiento en todos los espacios al servicio del ciudadano de acuerdo a lo estipulado en el decreto 0103 de 2015 de la ley 1712 de 2014 y en la ley 1618 de 2013 en la cual: "Se establecen términos perentorios y exigencias en la materia de accesibilidad universal de obligatorio cumplimiento". Adicionalmente, el decreto 561 de 2015 estipula "[...] las condiciones que deben tener los andenes y espacios públicos en Bogotá en el aparte de itinerario peatonal accesible, donde se incluyen los criterios de accesibilidad para los diseños, adecuaciones y construcciones en el espacio público de la ciudad" (Decreto 561 de 2015:02).

Teniendo esto en cuenta, resulta necesario cumplir con la legislación y la normatividad técnica vigente en materia de accesibilidad, para garantizar el derecho que tiene toda la población de la capital a disfrutar un espacio público y digno para todos.

Se informó sobre las acciones que se están desarrollando con el fin de implementar en los diseños, construcciones y adecuaciones futuras de espacios públicos peatonales en la ciudad, teniendo en cuenta los criterios de accesibilidad fundamentados en los documentos y la normatividad de la referencia y de estricto cumplimiento a nivel nacional.

\subsection{Actores $\mathrm{y} / \mathrm{o}$ instituciones involucradas}

Como actores, todos los peatones que a diario van a urbanizaciones en la carrera 17 entre calle 57 hasta la calle 67; los que viven o articulan entre la carrera 17 y los que llegan en el barrio y en la ciudad de Bogotá. Población, habitantes permanentes y temporales. Ciudadanos sin/con discapacidad.

También las siguientes instituciones y entidades estatales son actores importantes en el desarrollo de una política de accesibilidad universal: Instituto de Desarrollo Urbano, Secretaria Técnica Distrital de Discapacidad, Alcaldías Locales (Teusaquillo y Barrios Unidos), Comunidades de barrios, DADEP Departamento Administrativo de la Defensoría del Espacio Público, Bogotá, Secretaria Distrital de Planeación, Taller del Espacio Público, Universidades y ciudadanos.

\subsection{Causas probables de las dificultades en la movilidad peatonal: factores asociados}

\footnotetext{
2 La nueva agenda de Naciones Unidas. (23 de diciembre de 2016)
} 
Las obras que actualmente se desarrollan en el distrito capital en lo referente al mejoramiento y adecuación del espacio público, intersección vial andenes, pasos peatonales, vados y mobiliario no están cumpliendo con las especificaciones técnicas en materia de accesibilidad universal para las personas con discapacidad, adultos mayores, mujeres en estado de gestación, personas de talla baja, entre otros colectivos.

\section{FORMULACIÓN DEL PROBLEMA}

¿Cuáles son los principios que pueden guiar el diseño de una política pública de urbanismo y accesibilidad del el espacio público peatonal para la ciudad de Bogotá?

\section{OBJETIVOS}

\subsection{Objetivo general}

Formular los principios que permitan el diseño de una política pública en urbanismo y accesibilidad para la ciudad de Bogotá D.C.

\subsection{Objetivos específicos}

Identificar y clasificar los derechos de petición en materia de accesibilidad que recibe el Instituto de Desarrollo Urbano.

Identificar y Clasificar las necesidades de los ciudadanos en materia de Accesibilidad.

Identificar y clasificar el tipo de tráfico, ciudadanos y sus hábitos cotidianos.

Identificar los problemas y soluciones en las intersecciones viales en la carrera 17 con los flujos peatonales entre carrera 30 y Avenida Caracas (troncales Transmilenio).

\section{MARCO TEÓRICO}

Con propósitos de seleccionar elementos que permitan avanzar en la comprensión de la investigación, se retoman de forma global los ejes principales: accesibilidad en la movilidad peatonal; movilidad y exclusión social; y movilidad y el derecho de la ciudad. Se contempla inicialmente el concepto de movilidad peatonal y su incidencia en la consolidación de ciudades, de la misma forma se exponen los actores y variables a consideran en la intersecciones viales. A continuación se expone las principales características de la exclusión social y la relación que tiene está con la movilidad peatonal. De manera seguida, se presentan las principales características y elementos del concepto de accesibilidad peatonal.

\subsection{Accesibilidad en la movilidad peatonal}

Comprender la accesibilidad como la facilidad en el desplazamiento de los peatones $\sin$ / con discapacidad para acceder o interactuar en un espacio público, los andenes, cruces peatones y espacio peatonal, en términos prácticos implica que los peatones logren: llegar, ingresar, andar, salir, habitar, circular, ir, venir, caminar, pasar de los espacios de origen o destino.

\subsection{Ley de Universalidad}

El diseño universal aplicado a la movilidad peatonal tiene por objetivo principal la vida del peatón en la ciudad. El diseño universal debe ayudar a todas las personas con discapacidad ofreciéndole un margen de seguridad en el espacio peatonal pero no sólo a través de la instalación de rampas o borlados, se genera el conjunto de elementos de espacio público y mobiliario urbano que el entorno sea accesible y positivo para mejorar la calidad de vida.

A continuación, se acoge la versión 2.0 de 1 de abril de 1997, del Centro para el Diseño Universal (NC Stage University, The Center for Universal Desing, an initiative of the College of Design) ${ }^{3}$ y se adaptan los siete principios del diseño universal aplicados a la movilidad peatonal: ${ }^{4}$

3 "Universal Design Principles". Center for Universal Design. North Carolina State University. Raleigh, 1997. 
El primer principio: uso equitativo: el diseño es útil y comerciable a personas con discapacidad; el segundo principio: flexibilidad en el uso: el diseño debe acomodar a un amplio rango de preferencias y habilidades individuales; el tercer principio: sencillo o intuitivo: el espacio debe ser fácil de entender, atendiendo a la experiencia, conocimientos, habilidades lingüísticas o grado de concentración actual del usuario; el cuarto principio: información perceptible; el quinto principio: con tolerancia al error; el sexto principio: exija poco esfuerzo físico; y el séptimo principio: tamaño y espacio para el acceso y uso.

\subsection{Movilidad y exclusión social}

La exclusión social y la inclusión social no deben ser iguales ni perfectos, ni la inclusión social debe ser vista como la única solución a la exclusión social (Cañón, 2010). La exclusión social puede ser definida como: la situación que se produce como consecuencia de una o varias acciones llevadas a cabo por una sociedad en la cual un miembro de ésta se ve separado de su conjunto o de alguno de sus procesos más importantes. A pesar de tal discriminación y separación que sufren los afectados por la inclusión social, se les considera parte de la sociedad. Según los siguientes autores, la exclusión social es entendida de diferentes formas: La unión Europea, por su parte, define la exclusión como "la imposibilidad de gozar de los derechos sociales sin ayuda, en la imagen desvalorizada de sí mismo y de la capacidad personal de hacer frente a las obligaciones propias, en el riesgo de verse relegado de forma duradera al estatus de persona asistida y en la estigmatización que todo ello conlleva para las personas y, en las ciudades para los barrios den que residen" (Comisión de las Comunidades Europeas, 1992:9). Por otro lado, para Townsend es entendida como un fenómeno social, concreto y especifico, en el cual se incluye no sólo el padecer una privación económica de forma duradera, sino también la no participación en la ciudad (Townsend, 1979:61).

\subsection{Movilidad y el Derecho de la ciudad}

¿Qué es el derecho a la movilidad? La carta de derecho a la ciudad de las Naciones Unidas, en el artículo 13, Derecho al transporte público y la movilidad urbana, señala que es importante garantizar en las ciudades a todas las personas el derecho de movilidad y circulación en la ciudad, de acuerdo a un plan de desplazamiento urbano e interurbano y a través de un sistema de transporte público accesible, a precio razonable y adecuado a las diferentes necesidades ambientales y sociales (genero, edad y discapacidad) (Organización de las Naciones Unidas, 2005).

El documento de derecho a la ciudad demarcó la lista de derechos ciudadanos: Derechos a la identidad colectiva dentro de la ciudad; a la movilidad y a la accesibilidad; a la centralidad. ${ }^{5}$ Desde esta perspectiva, se identifica una población con discapacidad para centrarse en la diversidad, se genera el derecho a la diferencia individual en cuanto a cultura, lengua, capacidad, genero, edad, dimensiones y mucho más. Hay muchas diferencias entre discapacidad y accesibilidad.

\subsection{Accesibilidad en la historia de Bogotá y localidades de Teusaquillo y Barrios Unidos Imagen No.1 Normativa Nacional de Discapacidad y Accesibilidad en la historia de Bogotá, D.C.}

ACCESIBILIDAD EN LA HISTORIA DE BOGOTÁ D.C.

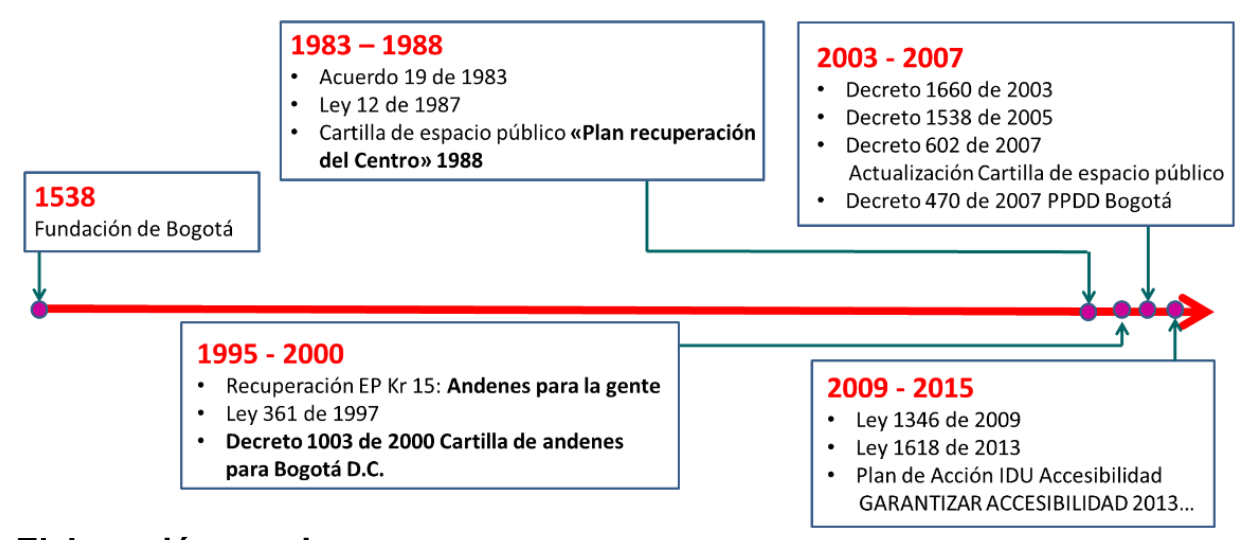

\section{Elaboración propia.}

\footnotetext{
${ }^{5}$ Derechos a la ciudad, los derechos ciudadanos. Jordi Borja.
} 


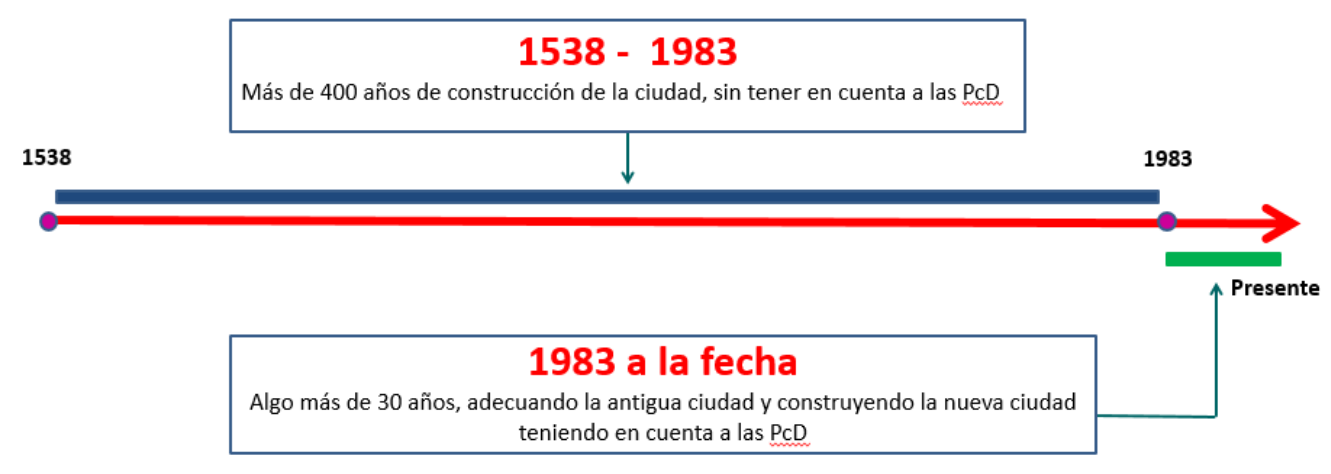

Imagen No. 2. Accesibilidad en la historia de Bogotá D.C. Elaboración propia

En la ciudad de Bogotá hay diferentes localidades. Barrios Unidos es la localidad número 12 de la ciudad, se ubica en el noroccidente de la ciudad y limita al occidente con la calle 63 , la cual la separa de la localidad de Teusaquillo; que a su vez la separa de la localidad de Chapinero con un terreno relativamente plano que forma parte de la sabana de Bogotá. Barrios Unidos cuenta con una gran oferta de bienes y servicios en zonas y barrios, tales como las zonas de comercios y servicios. Por su parte, Teusaquillo es la localidad número 13 de Bogotá. Se ubica el centro geográfico de la ciudad y limita al occidente con la localidad de Chapinero; está ubicada al lado de la localidad de Barrios Unidos. Este es un territorio completamente urbanizado, pero que aun así cuenta con muchas zonas verdes, además de zonas de comercio, educativas, de salud y administrativas.

Durante el siglo XXI, estas localidades han sido objeto de remodelación como resultado de la llegada del sistema masivo de transporte Transmilenio a la avenida Caracas y a la avenida carrera 30 . En consecuencia, han sido sometidas al mejoramiento de sus calles, andenes y espacios públicos en general. Las más importantes vías de Teusaquillo y Barrios Unidos son la calle 63 , la calle 53, la carrera 24 , la carrera 17, la avenida Caracas y la avenida Carrera 30; en sus principales vías cuentan con rutas de servicio público de buses, busetas, colectivos y Transmilenio, a las que llegan los peatones sin/con discapacidad en todos los barrios de dos localidades y la comunican con toda la ciudad. Ver las imágenes No.3 y 4.

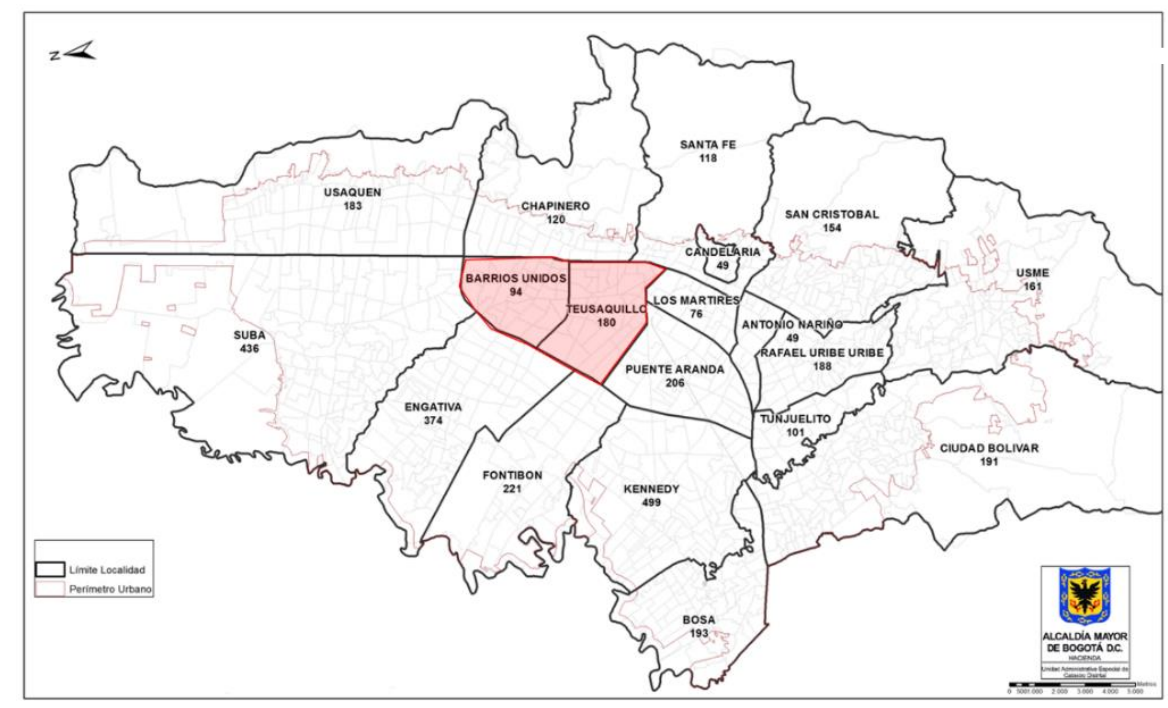

Imagen No. 3. Mapa de Bogotá con localidades. Alcaldía Mayor de Bogotá 


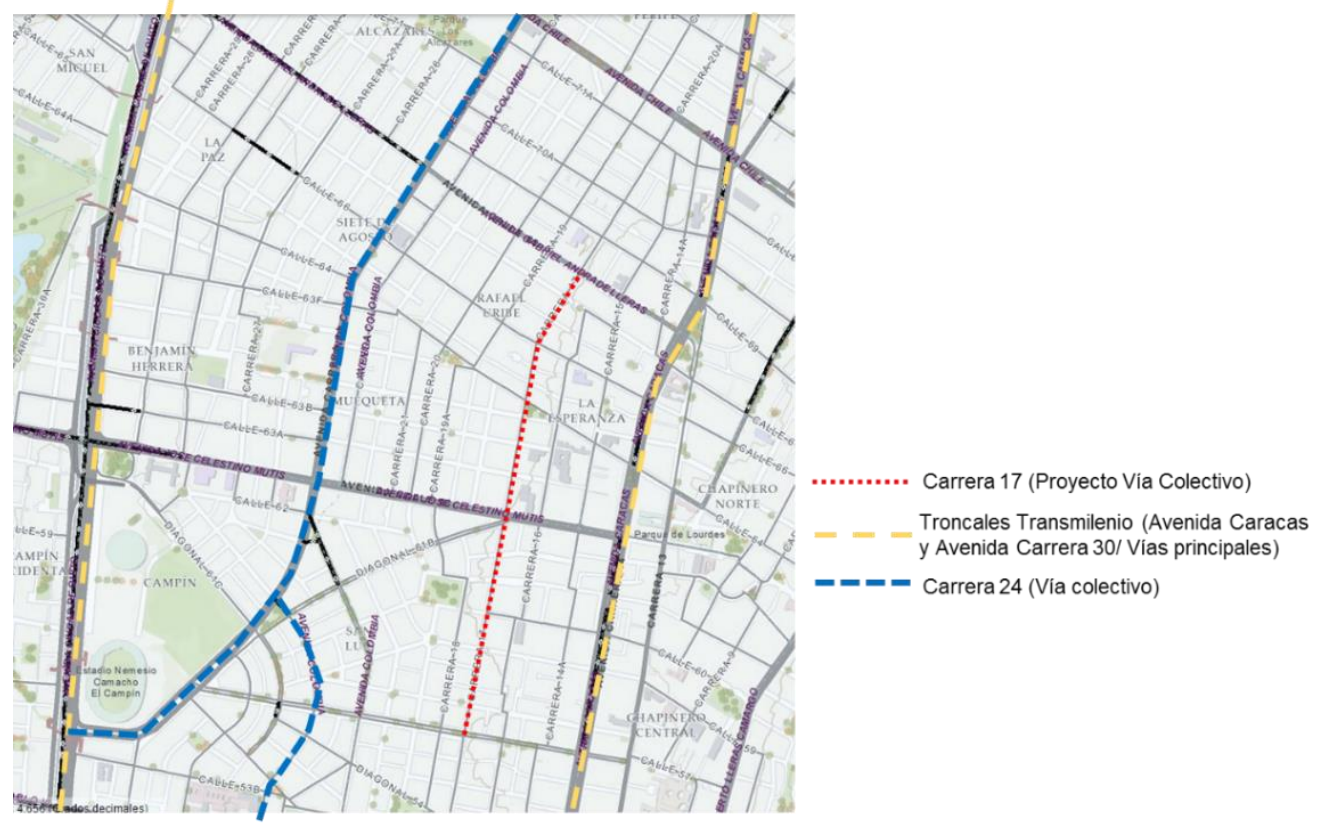

Imagen No. 4. La zona entre dos localidades Barrios unidos y Teusaquillo. Elaboración propia

\subsection{LOS MARCOS INTERNACIONALES Y NACIONALES DE DISCAPACIDAD Y ACCESIBILIDAD}

Hay que apreciarla a lo largo de un determinado periodo de tiempo de disposiciones internacionales: "La Declaración Universal de los Derechos Humanos se aprobó en 1948, pero hoy en día muchas personas no pueden ejercer sus derechos en igualdad de condiciones, ni son tratadas de forma plenamente equitativa en nuestra sociedad, como es el caso de las personas con discapacidad intelectual". 6 Teniendo en cuenta que la Declaración de los Derechos de las Personas con Discapacidad, proclamada por la Asamblea General de las Naciones Unidas el 9 de diciembre de 1975, la cual establece que: "la persona discapacitada tiene derecho a que se respete su dignidad humana y a disfrutar de una vida decorosa, lo más normal y plena que sea posible, cualquiera que sea el origen, la naturaleza o la gravedad de sus trastornos y deficiencias". ${ }^{7}$

En el año 1992 fue aprobada la Declaración de Cartagena sobre políticas integrales para las personas con discapacidad en el área Iberoamericana. Uno de los principales resultados del Decenio de las Naciones Unidas para los Impedidos fue la aprobación por la Asamblea General el 20 de diciembre de 1993 de las Normas Uniformes sobre la igualdad de oportunidades para las personas con discapacidad. ${ }^{8}$ De acuerdo del Decenio de las Naciones Unidas para los Impedidos fue la aprobación por la Asamblea General el 20 de diciembre de 1993 de las Normas Uniformes sobre la igualdad de oportunidades para las personas con discapacidad: "Aunque no se trata de un instrumento jurídicamente vinculante, las Normas Uniformes representan el firme compromiso moral y político de los gobiernos respecto de la adopción de medidas encaminadas a lograr la igualdad de oportunidades para las personas con discapacidad. Las Normas son un instrumento para la formulación de políticas y sirven de base para la cooperación técnica y económica" ((resolución 48/96:01). ${ }^{9}$

En el año 2006 las Naciones Unidas aprobaron una Convención sobre los Derechos de las Personas con Discapacidad la cual "establece que las personas con discapacidad tienen los mismos derechos que cualquier otra persona y que somos iguales ante la ley". ${ }^{10}$

Contexto Internacional: sobre los derechos de las personas con discapacidad y su protocolo facultativo de 13 de diciembre de 2006 de las Naciones Unidas (ONU).

\footnotetext{
${ }^{6}$ Declaración Universal de Derechos Humanos. http://www.un.org/es/documents/udhr/law.shtml (Consulta 15/12/16)

${ }^{7}$ Naciones Unidas 1970. La historia de la discapacidad y las naciones unidas http://www.un.org/spanish/disabilities/default.asp?id=574 (consulta 30/04/17)

${ }^{8}$ Normas uniformes sobre la igualdad de oportunidades para las personas con discapacidad.

http://www.un.org/spanish/disabilities/default.asp?id=498.

${ }^{9}$ Naciones unidas. Las normas uniformes sobre la igualdad de oportunidades para las personas con discapacidad. 1996 (Consulta 30/04/2017). http://www.un.org/spanish/disabilities/standardrules.pdf.

${ }^{10}$ La Convención Internacional sobre los Derechos de las Personas con Discapacidad.

www.un.org/esa/socdev/enable/documents/tccconvs.pdf
} 
Marco Constitucional Español: Marco constitucional de la accesibilidad y no discriminación para el acceso y utilización de los espacios públicos urbanizados.

Marco Normativo Autonómico: Ley Foral de Navarra, 5/2010 de 6 de abril, de accesibilidad universal y diseño para todas las personas.

Marco Legislativo y Reglamentario Estatal: Ordenan por orden cronológico de leyes de discapacidad y accesibilidad.

Considerando que el artículo 82 de la Constitución Política establece que "es deber del Estado velar por la protección de la integridad del espacio público y su destinación al uso común”.

Que el artículo 14 de la ley 1618 de 2013 establece que: "Las entidades del orden nacional, departamental, distrital y local garantizarán el acceso de las personas con discapacidad en igualdad de condiciones, al entorno físico, al transporte, a la información y a las comunicaciones, incluidos los sistemas y tecnologías de la información y las comunicaciones, el espacio público, los bienes públicos, los lugares abiertos al público y los servicios públicos, tanto en zonas urbanas como rurales".

Que mediante el Decreto Distrital 1003 de 2000, adicionada mediante Decreto Distrital 379 de 2002, actualizada mediante los Decretos Distritales 602 de 2007 y 561 de 2015, y se dictan otras disposiciones se adoptó la "Cartilla de Andenes de Bogotá D.C ". Como sistema constructivo de los mismos, se reglamentó el diseño y la construcción de andenes y espacios públicos de circulación peatonal del Distrito Capital.

Que el decreto Distrital 215 de 2005, por el cual se adoptó el "plan Maestro de Espacio Público para Bogotá Distrito Capital", el cual establece como estrategia de la política de calidad del Espacio Público, ampliar el ámbito de aplicación y complementar las directrices de la "Cartilla de Andenes".

Que mediante Decreto Distrital 602 de 2007: "Se actualizó la Cartilla de Andenes, adoptada mediante el Decreto Distrital 1003 de 2000, incorporando una alternativa de soluciones combinada de áreas duras y empradizas para andenes de vías locales en algunos proyectos de vivienda de interés prioritario VIP y algunos elementos para facilitar la integración al medio físico de personas con discapacidades motrices o visuales".

Que para el proceso de actualización de la Cartilla de Andenes, la Secretaría Distrital de Planeación en Coordinación con las Secretarías Distritales de Ambiente, Hábitat y Movilidad, el Jardín Botánico "José Celestino Mutis" y el Instituto de Desarrollo Urbano, identificaron los temas a revisar y "desarrollaron los aspectos de Ecourbanismo, accesibilidad e inclusión al medio físico a complementar y ajustar en la "Cartilla de Andenes" en aplicación de las políticas públicas de Discapacidad y Ecourbanismo y construcción Sostenible".

Que, en virtud de lo anterior, se hace necesario adoptar la presente actualización de la Cartilla de Andenes, incorporando, de manera integral, lineamientos técnicos de diseño y especificaciones técnicas de diseño y construcción orientados, por una parte, a garantizar el acceso a las personas con discapacidad, en igualdad de condiciones, al entorno físico y al espacio público del Distrito Capital y, por otra parte, a la implementación de prácticas sostenibles de urbanismo y construcción que contribuyan a la mitigación y adaptación de Bogotá a los efectos del cambio climático. Ver la imagen No. 5. 


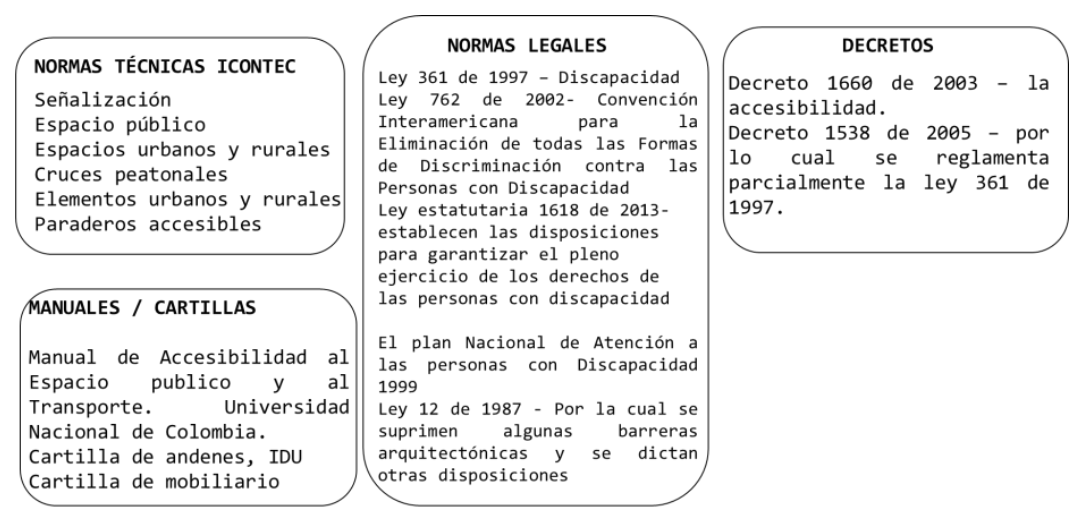

MARCO LEGAL NACIONAL

Imagen No. 5. Cuadro de marco legal nacional. Elaboración propia

\section{METODOLOGÍA PARA EL DIAGNÓSTICO Y MEJORAMIENTO DE ACCESIBILIDAD EN ZONAS DE ESPACIO PÚBLICO}

\subsection{Accesibilidad}

La ley 1618 de 2013, define accesibilidad como las "condiciones y medidas pertinentes que deben cumplir las instalaciones y los servicios de información para adaptar el entorno, productos y servicios, así como los objetos, herramientas y utensilios, con el fin de asegurar el acceso de las personas con discapacidad, en igualdad de condiciones, al entorno físico, el transporte, la información y las comunicaciones, incluidos los sistemas y las tecnologías de la información y las comunicaciones, tanto en zonas urbanas como rurales. Las ayudas técnicas se harán con tecnología apropiada teniendo en cuenta estatura, tamaño, peso y necesidad de la persona".

\subsubsection{Descripción y análisis del problema}

El espacio público, es un lugar de uso y acceso para todas las personas sin ninguna distinción física, racial, social, económica o política, las cuales tienen derecho al mismo. Pero, ¿cómo hacer para que el espacio público sea un lugar de uso colectivo en el que no se discrimine a ningún ciudadano o ciudadana, en especial a las personas con discapacidad?

En respuesta a lo anterior y desde la perspectiva del diseño, construcción, mantenimiento y conservación de estos lugares, es necesario que el mismo se conciba de tal manera que su forma y función no transgreda 0 violente los derechos de los ciudadanos, en especial los de aquellos o aquellas que se encuentran en condiciones vulnerables y/o de discapacidad. En síntesis, es necesario que el espacio público sea accesible e incluyente.

\subsubsection{Fase 1: diagnóstico}

Esta fase consiste en un recorrido de campo por los corredores que son objeto de intervención, a fin de evaluar su estado con respecto a las normas y manuales de accesibilidad anteriormente descritas (ver punto 1, Marco Normativo). En el desarrollo de esta fase se realiza la toma de datos en terreno. En esta actividad, se efectúan las siguientes tareas:

Identificación de fallas de accesibilidad en los corredores: Se realiza una inspección a los componentes que influyen en el tránsito peatonal, con el fin de determinar las fallas que presentan en materia de accesibilidad. La inspección se puede guiar en las NTC descritas en el punto 1 Marco Normativo. Los componentes que se analizan, se describen en la tabla No.1. 


\begin{tabular}{|l|l|l|}
\hline $\begin{array}{c}\text { Código } \\
\text { componente }\end{array}$ & Componente & \multicolumn{1}{|c|}{ Descripción } \\
\hline 1 & Andén & $\begin{array}{l}\text { Franja paralela a una vía vehicular destinada al tránsito de } \\
\text { peatones, ubicación de mobiliario urbano y redes de servicio } \\
\text { público, entre otros. }\end{array}$ \\
\hline 2 & Vado & $\begin{array}{l}\text { Es una modificación en el andén que consiste en rebajar el } \\
\text { sardinel para salvar el desnivel existente entre la acera y la } \\
\text { calzada. }\end{array}$ \\
\hline 3 & $\begin{array}{l}\text { Sendero } \\
\text { peatonal }\end{array}$ & $\begin{array}{l}\text { Es el recorrido longitudinal que existe en cualquier tipo de } \\
\text { superficie destinada al tránsito de peatones. }\end{array}$ \\
\hline 4 & $\begin{array}{l}\text { Esquina de } \\
\text { andén }\end{array}$ & $\begin{array}{l}\text { Es la parte final del sendero peatonal de un andén y se } \\
\text { encuentra siempre en las bocacalles (desembocadura de una } \\
\text { vía en otra de igual o mayor flujo vehicular). }\end{array}$ \\
\hline 5 & Cruce peatonal & $\begin{array}{l}\text { Es el paso permitido a las personas a través de una vía } \\
\text { vehicular. }\end{array}$ \\
\hline
\end{tabular}

Tabla 1 Componentes objeto de análisis. Elaboración propia

Las fallas de accesibilidad que se pueden detectar a nivel general en el terreno, se describen en la tabla No. 2. 


\begin{tabular}{|c|c|c|c|}
\hline Componente & Código falla & Falla de accesibilidad & \begin{tabular}{|lr} 
NTC & de \\
referencia & \\
\end{tabular} \\
\hline \multirow{7}{*}{ Andén } & 1.1 & $\begin{array}{l}\text { Ancho del andén inferior al mínimo } \\
\text { permitido }\end{array}$ & 4279 \\
\hline & 1.2 & $\begin{array}{l}\text { Andén sin continuidad en su recorrido } \\
\text { peatonal, por cambios de nivel en el } \\
\text { mismo }\end{array}$ & $4279-4143$ \\
\hline & 1.3 & $\begin{array}{l}\text { Andén con pendiente transversal, } \\
\text { superior al máximo permitido }\end{array}$ & 4143 \\
\hline & 1.4 & $\begin{array}{l}\text { Andén con pendiente longitudinal, } \\
\text { superior al máximo permitido }\end{array}$ & 4143 \\
\hline & 1.5 & $\begin{array}{l}\text { Andén sin señalética de piso para } \\
\text { invidentes }\end{array}$ & 5610 \\
\hline & 1.6 & $\begin{array}{l}\text { Andén con señalética de piso para } \\
\text { invidentes mal instalada }\end{array}$ & 5610 \\
\hline & 1.7 & $\begin{array}{l}\text { Andén sin continuidad en su recorrido } \\
\text { peatonal por la presencia de } \\
\text { obstáculos o barreras físicas }\end{array}$ & 4279 \\
\hline \multirow{4}{*}{ Vado } & 2.1 & Ancho vado menor al mínimo permitido & 4143 \\
\hline & 2.2 & $\begin{array}{l}\text { Porcentaje de pendiente vado mayor al } \\
\text { máximo permitido }\end{array}$ & 4143 \\
\hline & 2.3 & \begin{tabular}{|l} 
Vado sin señalética de piso para \\
invidentes
\end{tabular} & $4143-5610$ \\
\hline & 2.4 & $\begin{array}{l}\text { Remate rampa vado con respecto a } \\
\text { calzada, diferente a } 0,0\end{array}$ & 4143 \\
\hline \multirow{7}{*}{ Sendero peatonal } & 3.1 & $\begin{array}{l}\text { Ancho del sendero inferior al mínimo } \\
\text { permitido }\end{array}$ & 4279 \\
\hline & 3.2 & $\begin{array}{l}\text { Sendero sin continuidad en su } \\
\text { recorrido peatonal, por cambios de } \\
\text { nivel en el mismo }\end{array}$ & 4143 \\
\hline & 3.3 & $\begin{array}{l}\text { Sendero sin señalética de piso para } \\
\text { invidentes }\end{array}$ & 5610 \\
\hline & 3.4 & $\begin{array}{l}\text { Sendero con señalética de piso para } \\
\text { invidentes mal instalada }\end{array}$ & 5610 \\
\hline & 3.5 & $\begin{array}{l}\text { sendero con pendiente transversal, } \\
\text { superior al máximo permitido }\end{array}$ & 4143 \\
\hline & 3.6 & $\begin{array}{l}\text { sendero con pendiente longitudinal, } \\
\text { superior al máximo permitido }\end{array}$ & 4143 \\
\hline & 3.7 & $\begin{array}{l}\text { Sendero sin continuidad en su } \\
\text { recorrido peatonal por la presencia de } \\
\text { obstáculos o barreras físicas }\end{array}$ & 4279 \\
\hline \multirow{3}{*}{$\begin{array}{l}\text { Esquina de } \\
\text { andén }\end{array}$} & 4.1 & Esquina de andén sin acceso* & 4143 \\
\hline & 4.2 & $\begin{array}{l}\text { Esquina de andén sin señalética de } \\
\text { piso para invidentes }\end{array}$ & 5610 \\
\hline & 4.3 & Esquina de andén con barreras físicas & NE \\
\hline \multirow[t]{5}{*}{ Cruce peatonal } & 5.1 & Cruce peatonal sin vados & 4143 \\
\hline & 5.2 & $\begin{array}{l}\text { Cruce peatonal sin alineación en los } \\
\text { vados }\end{array}$ & 4143 \\
\hline & 5.3 & \begin{tabular}{|l}
$\begin{array}{l}\text { Separador vial cruce peatonal, no } \\
\text { accesible }\end{array}$ \\
\end{tabular} & NE \\
\hline & 5.4 & $\begin{array}{l}\text { Cruce peatonal sin garantía, por estar } \\
\text { sobre una vía destapada o a riesgo. }\end{array}$ & NE \\
\hline & 5.5 & $\begin{array}{l}\text { Cruce peatonal sobre vía férrea, no } \\
\text { accesible }\end{array}$ & NE \\
\hline
\end{tabular}

* Aplica para esquinas de andén en vías locales o con cruce peatonal autorizado por Secretaría de Movilidad. NE No Existe.

Tabla 2 Fallas de accesibilidad por componente objeto de análisis

6.1.3 Registro fotográfico fallas de accesibilidad: Una vez detectada la falla de accesibilidad, se toman las fotografías necesarias para su detalle.

Categoría de discapacidad: Identificación de la discapacidad, como por ejemplo, una barrera física, que es cualquier tipo de obstáculo que dificulta y en muchos casos, imposibilita la circulación peatonal, especialmente, la circulación de personas con discapacidad y movilidad reducida.

Toma de dimensiones básicas: Según el componente y la falla detallada en las fotografías, se procede a tomar sus dimensiones básicas. Las dimensiones básicas que se toman en el terreno son: ancho del andén, anchos esquina andén, ancho - recorrido y pendiente de los vados, junto con las demás dimensiones que estimen los técnicos de accesibilidad, que sean específicas del terreno y que se deseen detallar en el 
diagnóstico.

Procedimiento para la toma de datos en terreno. Para recopilar la información descrita, se utiliza el formato que se describe en la tabla No.3.

\begin{tabular}{|c|c|c|c|c|c|}
\hline TRAMO_ & LOCALIDAD & & FECHA & _ELABORÓ & HOJA_ DE \\
\hline \multirow{2}{*}{ Dirección - costado } & \multicolumn{2}{|c|}{ Regis tro fotográfico } & \multirow{2}{*}{$\begin{array}{c}\text { código } \\
\text { componente } \\
\text { analizado }\end{array}$} & \multirow{2}{*}{ Dimensiones } & \multirow{2}{*}{$\begin{array}{c}\text { código Falla } \\
\text { de } \\
\text { accesibilidad }\end{array}$} \\
\hline & de la & & & & \\
\hline & & & & & \\
\hline & & & & & \\
\hline & & & & & \\
\hline & & & & & \\
\hline & & & & & \\
\hline
\end{tabular}

Tabla 3. Facsímil del formato para la toma de datos en terreno. Elaboración propia.

Instrucciones para el diligenciamiento del formato para la toma de datos en terreno. La información que se debe diligenciar en el encabezado del formato es la siguiente:

Tramo analizado: en este campo se debe escribir el mismo nombre, número o código que se utilizó para nombrar el corredor dentro de la priorización.

Localidad: en este campo se debe escribir el nombre de la localidad a la que pertenece el eje.

Fecha: en este campo se diligencia la fecha cuando se toman los datos.

Elaboró: en este campo se escriben los nombres de los técnicos que recopilan la información.

Hoja_de_: en este campo se escribe el número de la hoja tramitada con respecto al total de hojas que salen durante el diagnóstico por tramo.

Nota: el número de hojas refieren a las necesarias para analizar el tramo y no al total de las realizadas en una jornada de trabajo.

La información que se debe diligenciar en el cuerpo del formato es la siguiente:

Dirección - costado: en este campo se escribe la dirección y el costado del componente donde se detecta la falencia.

Registro fotográfico - de la, a la: en este campo se escribe el número de serie (según la carpeta donde se guardan los archivos) de las fotos que se toman del componente, para el detalle de la falencia. Ejemplo: de la 10 a la 20.

Código componente analizado: en este campo se escribe el código del componente donde se detecta la falencia (ver tabla 3).

Dimensiones: en este campo se escriben las dimensiones básicas del componente donde se detecta la falencia, tomadas en terreno.

Código falla de accesibilidad: en este campo se escribe el código de la falla que se detalla para el componente (ver tabla 3).

\subsubsection{Elaboración del documento técnico de soporte}

En esta actividad se realizan las siguientes tareas:

Formulación de las recomendaciones de accesibilidad. Para esta tarea se diseñaron un total de 12 fichas de accesibilidad y se utilizó la Cartilla de Andenes del Instituto de Desarrollo Urbano. Específicamente, las fichas contienen esquemas de andenes, vados, esquinas de andén, cruces peatonales y rampas para senderos peatonales, con indicaciones y/o recomendaciones generales basadas en el marco normativo NTC expuesto.

La información consignada en las fichas es la siguiente, ver tabla No. 4 


\begin{tabular}{|c|c|c|}
\hline $\mathrm{N}^{\circ}$ & CONTENIDO & $\begin{array}{l}\text { NTC de } \\
\text { referencia }\end{array}$ \\
\hline 1 & $\begin{array}{l}\text { En esta ficha se consignan los lineamientos generales para la } \\
\text { utilización de la señalética de piso para invidentes y la pendiente } \\
\text { transversal de un sendero peatonal. }\end{array}$ & $4279-5610$ \\
\hline 2 & $\begin{array}{l}\text { En esta ficha se consignan los lineamientos generales para un vado. } \\
\text { Es de anotar que la NTC } 41343 \text { sugiere un ancho mínimo de } 0.9 \mathrm{~m} \text {. En } \\
\text { esta ficha se sugiere un ancho mínimo de } 2.0 \mathrm{~m} \text { y el máximo de } \\
\text { acuerdo al ancho de la zona de circulación peatonal. }\end{array}$ & $4143-5610$ \\
\hline 3 & $\begin{array}{l}\text { En esta ficha se consignan los lineamientos generales de accesibilidad } \\
\text { para una esquina estándar de andén. Una esquina estándar se ubica } \\
\text { en andenes que van de } 2.8 \mathrm{~m} \text { en adelante. }\end{array}$ & $4143-5610$ \\
\hline 4 & $\begin{array}{l}\text { En esta ficha se consigna los lineamientos generales de accesibilidad } \\
\text { para una esquina deprimida. Llamada así, porque su borde externo es } \\
\text { rebajado hasta el nivel de la calzada. Se utilizan en andenes de alto } \\
\text { flujo peatonal y con anchos superiores a los } 3.2 \mathrm{~m}\end{array}$ & $4143-5610$ \\
\hline 5 & $\begin{array}{l}\text { En esta ficha se consignan los lineamientos generales para la esquina } \\
\text { de andén angosto. Un andén angosto va desde los } 1.2 \mathrm{~m} \text {, hasta los } 2.8 \\
\mathrm{~m} \text {. En esta clase de esquina, su borde externo es rebajado hasta el } \\
\text { nivel de la calzada, debido a que sus dimensiones no permiten la } \\
\text { construcción de un vado de acuerdo a las normas. }\end{array}$ & 4143 \\
\hline 6 & $\begin{array}{l}\text { En esta ficha se consignan los lineamientos para salvar un cambio de } \\
\text { nivel en el andén y así brindar continuidad en su recorrido peatonal. }\end{array}$ & $\begin{array}{l}4143-4279- \\
5610\end{array}$ \\
\hline 7 & $\begin{array}{l}\text { En esta ficha se consignan los lineamientos generales para un } \\
\text { separador vial }\end{array}$ & NE \\
\hline 8 & $\begin{array}{l}\text { En esta ficha se consignan los lineamientos generales para un cruce } \\
\text { peatonal estándar. Estos cruces son típicos en vías intermedias y } \\
\text { locales. }\end{array}$ & 4143 \\
\hline 9 & $\begin{array}{l}\text { En esta ficha se consignan los lineamientos generales para un cruce } \\
\text { peatonal con separador vial. Aunque la norma NTC } 4143 \text {, menciona la } \\
\text { necesidad de alinear los vados en un cruce peatonal, no existe una } \\
\text { norma específica NTC que indique un cruce con separador. }\end{array}$ & NE \\
\hline 10 & $\begin{array}{l}\text { En esta ficha se consignan los lineamientos generales para una rampa } \\
\text { escalonada, recomendada para senderos peatonales con una } \\
\text { pendiente longitudinal superior al } 12 \% \text {. Ejemplo, senderos peatonales } \\
\text { en zonas de montaña, parques con loma, subidas con pendientes } \\
\text { pronunciadas, etc. }\end{array}$ & NE \\
\hline 11 & $\begin{array}{l}\text { En esta ficha se consignan los lineamientos generales para garantizar } \\
\text { diferenciar y resaltar un cruce peatonal, en una vía en mal estado o un } \\
\text { cruce a riesgo }\end{array}$ & NE \\
\hline 12 & $\begin{array}{l}\text { En esta ficha se consignan los lineamientos generales para cruce } \\
\text { peatonal sobre una línea férrea }\end{array}$ & NE \\
\hline
\end{tabular}

NE No Existe

Tabla 4 Contenido fichas de accesibilidad

\subsubsection{Recomendaciones de la comunidad (Participación de las PcD en el Diseño - Codiseño)}

Con el fin de acompañar a nivel social la intervención hacia el espacio púbico en el segmento priorizado, se propone a los gestores de la Secretaría Técnica de Discapacidad como en los Consejos Locales de Discapacidad, diseñar e implementar herramientas sociales que logren complementar los cabildos ciudadanos realizados previamente con talleres de imaginarios sociales ${ }^{11}$ los cuales tendrán la finalidad de facilitar procesos comunitarios para la generación de lineamientos de diseño y apropiación del espacio público según las necesidades y expectativas de la comunidad.

Contemplar los imaginarios sociales como fundamentales en estos procesos comunitarios hacia el urbanismo, les permite a los sujetos de una sociedad que se identifiquen y se sientan parte fundamental del escenario en donde convergen con otros actores. Estos atributos identitarios que se complementan con el legado histórico de cada contexto, facilitan en los sujetos una autodeterminación y prácticas de cooperativismo que les permite

\footnotetext{
${ }^{11}$ Los talleres de imaginarios, estrategia de urbanismo Cívico - Pedagógico, Empresa de Desarrollo Urbano (Municipio de Medellín) http://www.edu.gov.co/site/actualidad/615-gestionsocialuva
} 
distinguirse a nivel socio-territorial de otros grupos poblacionales. Por ende, debe tenerse en cuenta que "la sociedad es un conjunto de significaciones imaginarias sociales cuya vida se encarna en las instituciones capaces de transformar y de conferirle sentido a los aconteceres" (Pintos 1995:61).

Esta capacidad de transformar requiere de dos elementos fundamentales, el primero es la conformación de la psique de los individuos, quienes crean una representación del mundo, no sólo como un constructo intelectual, sino con el segundo elemento fundamental, la creación del impulso de la sociedad que se conforma por las emociones e impulsos del hombre, que al colectivizarse se convierten en prácticas sociales, racionales e imaginativas que ayudan a la transformación de un entorno determinado: "[...] bajo esta dimensión se construye e instituye una manera de pensar la sociedad no tanto desde lo determinable, sino más bien de la creación indeterminada e incesante de la sociedad, de sus producciones y los significados, sentidos y prácticas que se movilizan con esas producciones" (Vásquez 2001:29).

Comprender la incidencia de los imaginarios sociales en la explicación fenomenológica de la sociedad, no sólo contempla los dos niveles de profundización ya mencionados, sino que también permite asumir que los imaginarios son múltiples construcciones mentales construidas y colectivizadas que dan sentido a la vida tal como se menciona a continuación: "Más allá de cierto plano de descripciones fundamentales, y sobre todo ese algo no se da completamente en la superficie y en una apariencia concreta, la tarea que se asigna la actividad mental es la construcción plausible o convincente de la realidad" (Baeza 2004:41).

De esta forma, se entiende que la explicación de los fenómenos sociales o de las acciones cotidianas de un entorno especifico no sólo se puede exponer bajo esquemas de racionalidad objetiva y tajante, propias de la modernidad, sino que además permite comprender que los imaginarios, como representaciones mentales que acogen imágenes, percepciones, emociones y sentimientos de los individuos, explican en gran medida comportamientos, acciones hermenéuticas de comunidades que abren la posibilidad de representar simbólicamente lo que sucede. Adicionalmente, cabe aclarar que es el lugar en donde se expresan los deseos, así insatisfacciones y expectativas con lo cual se preservan o generan cambios sociales.

Para realizar cambios en la sociedad a través de los imaginarios sociales, se requiere de un parámetro valorativo y de dispositivos de validez donde los sujetos legitimen dichas representaciones simbólicas como explicativas e interpretativas de la realidad. El imaginario responde entonces a la necesidad de posicionamiento de los individuos en un intento por explicarse su relación y posición ante la realidad, sin que ello relegue la importancia de la imaginación como un vehículo para entender el modo en el que ha funcionado y funciona el mundo, para suplir o transformar insatisfacciones comunitarias en pro de la reconstrucción de escenarios concretos en los que se desenvuelven los sujetos sociales.

\subsection{Metodología de los Talleres de Imaginarios Sociales (Participación Concejo local de discapacidad - Codiseño)}

\section{Jornada de sensibilización:}

Para dar inicio a este taller se requiere empezar con una jornada de sensibilización pedagógica en el que se proyecte a las personas de entidades públicas de Bogotá la necesidad de reconocerse como sujetos activos de derecho y por ende, gestores de su propio desarrollo, cuyo ejercicio participativo es fundamental para la planeación integral y objetiva de la ciudad.

Por esta razón se proponen diferentes ayudas visuales que contribuyan con la sensibilización, y en consecuencia, con la toma de conciencia sobre la importancia de planear conjuntamente como medio de transformación y cambio social; por lo tanto, esta ayuda pretende especificar o profundizar en los siguientes componentes:

¿Qué es planear?

Ciclo de la planeación

¿Quiénes Planean?

¿Qué planeamos?

¿Cuáles son los puntos de barreras urbanísticas?

¿Cuáles son los puntos de ciudad accesible para mejorar la vida e inclusión social?

Detección y comprensión de necesidades y problemas sociales del sector a intervenir: 
Después de haber generado un acercamiento importante con la comunidad de locales y de haber tenido la posibilidad de profundizar sobre la importancia de generar redes sociales o fortalecer tejidos sociales para la planeación participativa, se entrará a enunciar, detectar, georreferenciar y comprender las necesidades o problemáticas sociales que los mismos habitantes del sector padecen.

Enumeración: En este momento, la comunidad de manera participativa y colectiva, empieza a enumerar las problemáticas sociales que evidencian en los diferentes sectores que implican cada una de las áreas de intervención.

Georreferenciación: Después de haber detectado aquellos núcleos problemáticos, se procede a georreferenciar a través una herramienta metodológica de cartografía social, en la que la misma comunidad o actores cualificados para la participación, elaboran un mapa de su sector y empiezan a dibujar y centralizar puntos del territorio que tienden a ser complejos por la presencia de dichas deficiencias sociales. El ejercicio de ubicar en un mapa aquellos puntos o epicentros con necesidades sociales, debe estar acompañado de un mapeo de puntos o escenarios que den cuenta de sentimientos de identidad, el cual puede tomar como base los sectores de interés cultural evocados hacia el patrimonio cultural material e inmaterial.

La cartografía social responde a este gran argumento de Paulo Freire quien expone que: "La tierra de la gente es su geografía, ecología, su topografía y biología. Ella es tal como organizamos su producción, hacemos su historia, educación, su cultura, su comida y su gusto al cual nos acostumbramos. La tierra de las personas implica lucha por sueños diferentes a veces antagónicos como los de sus clases sociales mi tierra no es, finalmente una abstracción" (Freire, 1997).

Lo interesante de esta herramienta metodológica, es que permite evidenciar que el mapa del territorio en el que la comunidad vive, es realizado por ellos mimos en su ejercicio de cooperación y trabajo colectivo, que facilitan el intercambio de saberes y de percepciones territoriales, que configuran todo un escenario y por ende, lo ordenan según las dinámicas socio culturales que se inscriben en dicho espacio.

Por lo tanto, es una construcción con un lenguaje propio, en el que la simbología es fundamental a la hora de representar aquellos epicentros problemáticos o de conservación de patrimonio cultural, pues más allá de homogenizar ciertos caracteres, es la posibilidad para redescubrir otra forma de representarlos y por ende, de ubicarlos: "Es un ejercicio colectivo de reconocimiento del entorno socio-territorial a través de la construcción de mapas; con este ejercicio se evidencian las relaciones sociales, se develan saberes que permite a sus participantes un mejor conocimiento de su realidad, genera espacios de reflexión y permite construir un lenguaje común de interpretación de las diferentes percepciones de la realidad presente en las comunidades" (López, 2005:01). ${ }^{12}$

Para poder llevar a cabo la cartografía social es necesario precisar algunos instrumentos que se consideran fundamentales para dicha herramienta metodológica: los mapas, planos y elementos volumétricos para acercarse a la representación de alturas, densidades y localizaciones de las estructuras del sector, observación participante, encuesta de percepción e ideas (post it).

Instrumentos vivenciales como: talleres, trabajo en equipo, recorridos de campo, narración de experiencias cotidianas, plenarias, creación simbólica, material visual, entrevistas, videos y fotos.

\section{Visualización de expectativas sobre la transformación del sector a partir de preguntas detonadoras:}

¿Qué ventajas y desventajas tiene estar en el sector?

¿Qué ventajas y desventajas tendría que hicieran cambios en el sector?

¿Cuál es el lugar más seguro del sector y por qué?

¿Cuál es el lugar más peligroso del sector y por qué?

¿Cuál es el color que identifica tu sector y por qué?

¿Cuál es la figura de poder que más ha influido en la realidad del sector?

¿Con qué sentimiento le gustaría que fuera identificado su sector?

¿Considera que permanecer en este territorio le genera beneficios económicos?

\footnotetext{
${ }^{12}$ Lopez, Luis Molina, La cartografía social y su aplicación a la planificación municipal y regional. Grupo de estudio urbano regional del Magdalena Medio Unipaz, Villavicencio, Septiembre de 2005.
} 
¿Qué se ha ganado y perdido en los últimos cinco años? ${ }^{13}$

Cada una de las preguntas comprende categorías de análisis como: permanencia, ubicación, sostenibilidad (ambiental, equipamientos, servicios, económica y religioso), seguridad, movilidad y otros.

Esta visualización permite a los participantes de la comunidad, retomar aquella memoria histórica y legado propio del sector, para asumir cierta postura de pertenencia al territorio, recordando, manifestando inquietudes, temores e inconformidades hacia el mismo. Esta acción permitirá un avance significativo en los demás procesos participativos pues se centrará a la proposición y comprensión exhaustiva de las dinámicas territoriales que ordenan el sector.

Reflexiones sobre el territorio: Para este proyecto se requiere trabajar bajo dos supuestos planteados previamente por Armando Silva en su texto "Imaginarios Urbanos":

Ciudad Vista: entendida como aquella instancia que tiene en cuenta los diferentes puntos de vista de los ciudadanos frente a la ciudad (lectura colectiva a la misma); esta instancia de leer a la ciudad, lo que no sólo implica el conocimiento y la georreferenciación de lugares específicos, sino acoger la interpretación, la narración, los escritos que la población realiza hacia su territorio - ciudad.

Ciudad Imaginada: la forma de imaginar la ciudad está articulada con la imaginación simbólica que se da cuando el significado "[...] no se podrá presentar con una cosa específica, en cuanto tal, una palabra exacta o una descripción única, y lo que presenta es más que una cosa, un sentido o muchos que pueden abarcar la expresión simbólica" (Silva, 2006: 91). Por tal, la ciudad imaginada es una ciudad es ese anhelo de las y los niñas, jóvenes, ciudadanas y ciudadanos frente a su territorio, donde se interpreten sus representaciones de ciudad y por ende sus intenciones sociales.

Estas intenciones sociales se articularán con los elementos y principios del Principios de Desarrollo Urbano para el transporte en la vida urbana ${ }^{14}$ (Transit-oriented development TOD Standard, 2017), (Compactar, Densificar, Mezclar, Conectar, Caminar, Pedalear, Transitar y Cambiar) como propuesta urbanística integral e incluyente (ver imagen No. 5).

\footnotetext{
${ }^{13}$ Fuente: Programa Progresa Fenicia (Resultados de los talleres de Diseño Urbano participativo). Universidad de los Andes; Junio de 2012

${ }^{14}$ TOD Standard, UN Hábitat. (Consulta: 25/04/2017) https://www.itdp.org/tod-standard/
} 

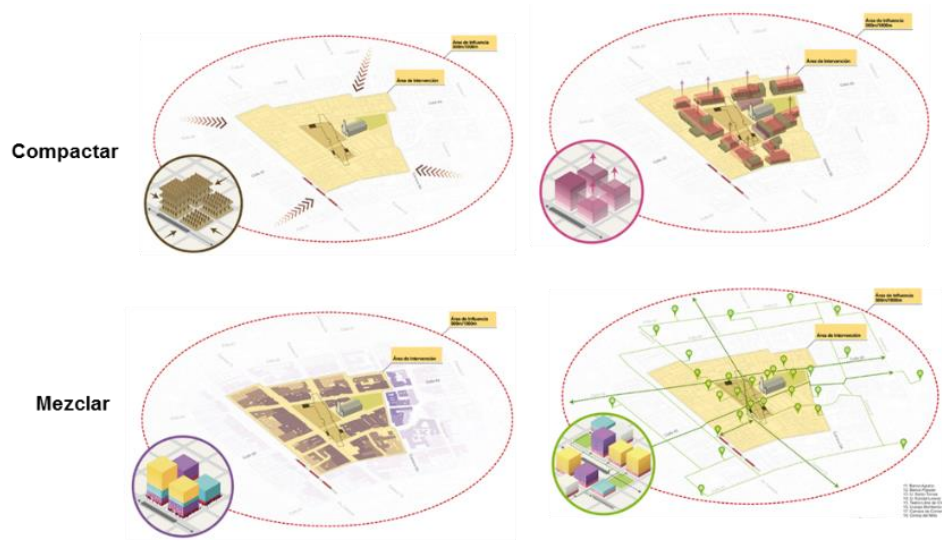

Caminar
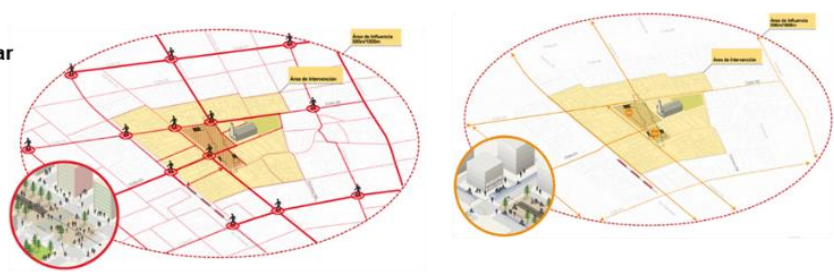

Pedalear

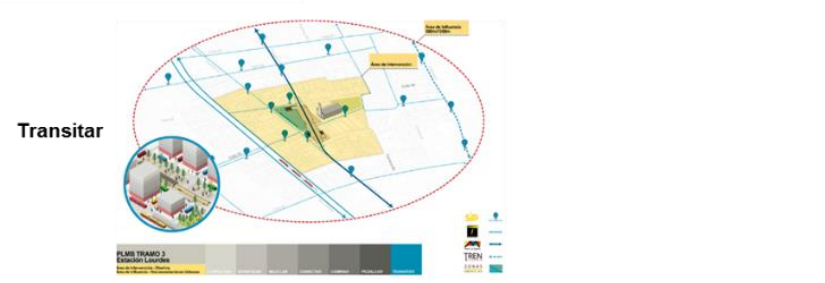

Imagen No. 5 Eelementos y principios del Desarrollo Urbano para el transporte en la vida urbana. Elaboración propia

Teniendo en cuenta lo anterior, es necesario que en el taller el grupo se divida en subgrupos, para que posteriormente se entregue a cada uno de ellos 2 planos (uno con el sector actual y otro sin edificaciones), marcadores, papeles de colores, bloques de madera y tijeras.

\begin{tabular}{|l|l|}
\hline Primer Plano (Ciudad Vista) & Segundo Plano (Cuidad Imaginada) \\
\hline $\begin{array}{l}\text { En esta se georreferenciaran }{ }^{15} \text { los núcleos } \\
\text { problemáticos (PUI) que se evidenciaron } \\
\text { anteriormente. }\end{array}$ & $\begin{array}{l}\text { Se plantea la posibilidad de especificar qué cosas } \\
\text { se desea que se conserven (flujos de circulación y } \\
\text { localización de actividades). }\end{array}$ \\
\hline $\begin{array}{l}\text { Se evidencia lo que hay actualmente (flujos } \\
\text { de circulación y localización de } \\
\text { actividades). }\end{array}$ & $\begin{array}{l}\text { A partir de los flujos identificados, se indaga sobre } \\
\text { la posible localización de las actividades que } \\
\text { existen y otras que desea que existan. Los } \\
\text { elementos se identificarán con los cubos o figuras } \\
\text { representativos de las actividades, equipamientos } \\
\text { y demás elementos que contribuyan a reconstruir } \\
\text { ciudad. }\end{array}$ \\
\hline
\end{tabular}

Cada grupo debe identificar elementos a conservar, flujos de circulación y localización de actividades. Todo debe localizarse en el plano: se inicia con ¿qué cosas desean conservar del sector? Posteriormente, con marcadores de diferentes colores debían identificar los flujos de circulación de: los residentes de la zona, la gente que trabaja en la zona, los estudiantes, los turistas, otros flujos. A partir de los flujos identificados, se

\footnotetext{
${ }^{15}$ Es un ejercicio colectivo de reconocimiento del entorno socio-territorial a través de la construcción de mapas; con este ejercicio se evidencian las relaciones sociales, se develan saberes que permite a sus participantes un mejor conocimiento de su realidad, genera espacios de reflexión y permite construir un lenguaje común de interpretación de las diferentes percepciones de la realidad presente en las comunidades.
} 
indaga sobre la posible localización de las actividades que existen y otras que se desea que existan. Cada zona se identificó con papeles de colores sobre el plano. ${ }^{16}$

Exploración sobre la idea de "tipos" de construcciones. Se trabaja con los bloques de madera conformando diferentes formas de edificaciones y ocupación, para reflexionar sobre los efectos que tiene en el espacio. Los bloques tienen los mismos colores de los papeles usados para la zonificación de actividades.

\section{Slogan de ciudad:}

Con este instrumento se pretende crear un slogan de carácter artístico a partir de los resultados de los talleres de imaginarios sociales, en donde plasmen cómo creerían o imaginarían la reconstrucción de ciudad acogiendo elementos como la inclusión social y desarrollo integral del sector.

Elaboración de esquemas de localización: fallas y recomendaciones de accesibilidad. Una vez realizada la formulación de recomendaciones - tanto generales como especiales - para cada falencia detectada en el diagnóstico, se procede a realizar su localización en un plano (ver imágenes 7 y 8).
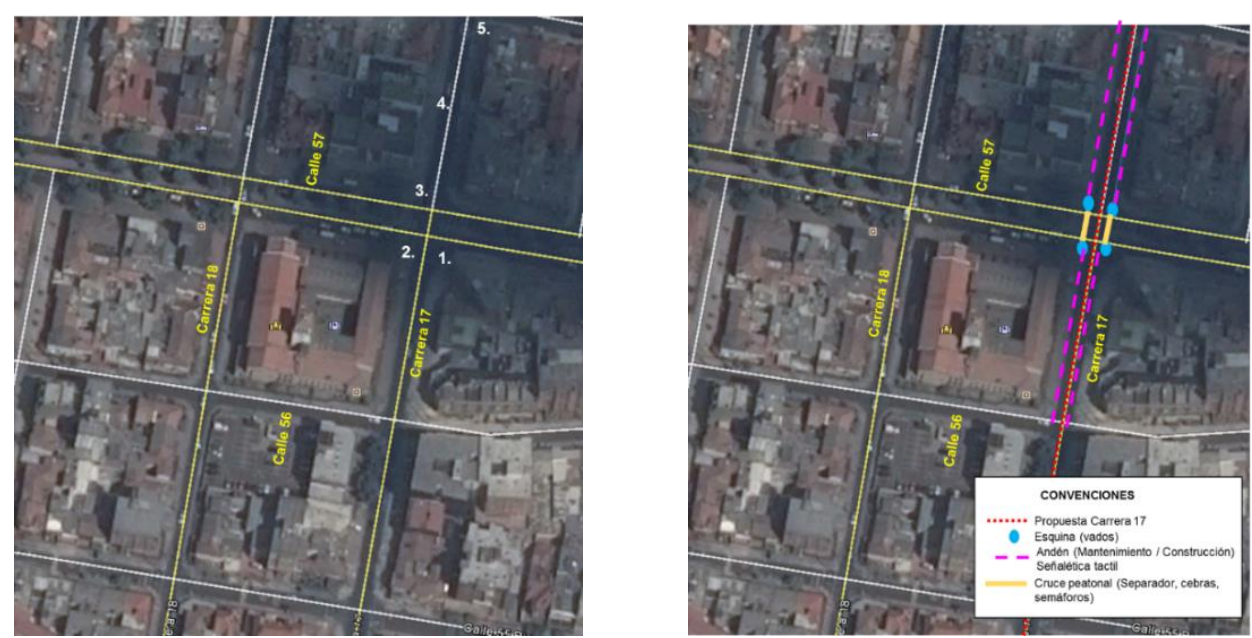

Imágenes No. 7 y 8 Plano de localización general de las fallas accesibilidad (Izquierdo). Y Plano general de recomendaciones de accesibilidad (Derecha). Elaboración propia.

Con los resultados del diagnóstico y sus respectivas recomendaciones se elaboran dos tablas: la primera tabla, numera y detalla (tramo por tramo) cada una de las fotos de los puntos donde se detectó la falla, su dirección, costado y enfoque (hacia donde mira la foto), diagnóstico (componente analizado y su falla de accesibilidad), las recomendaciones y su localización general (ver imagen 9).

\footnotetext{
${ }^{16}$ Fuente: Programa Progresa Fenicia (Resultados de los talleres de Diseño Urbano participativo). Universidad de los Andes; Junio de 2012.
} 


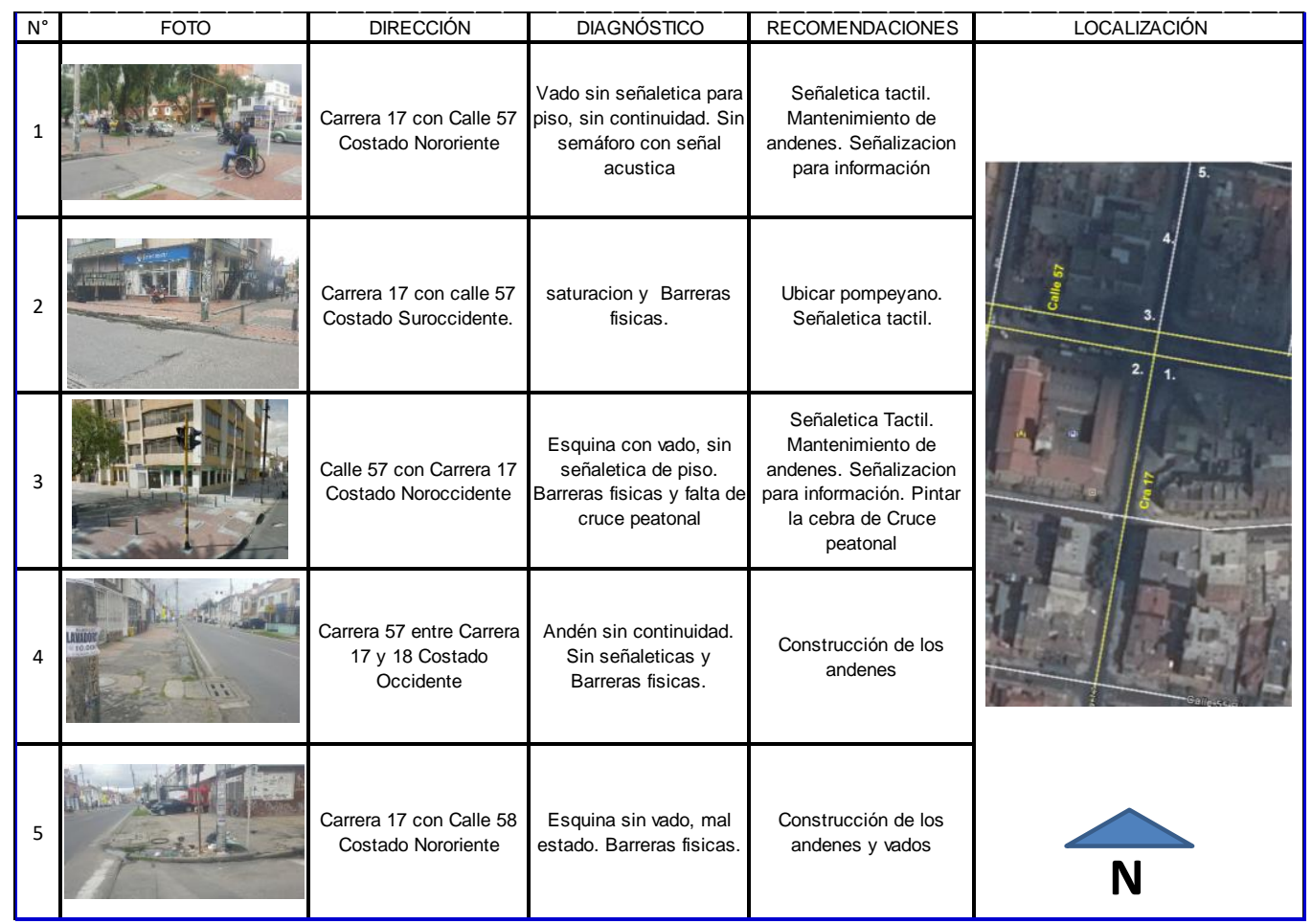

Imagen 9. Tabla con el resumen del diagnóstico y recomendaciones de accesibilidad. Elaboración propia.

\section{CONCLUSIONES / RESULTADOS}

Existe espacio público peatonal construido en Bogotá no es accesible, por lo tanto, es necesario desarrollar una política pública en urbanismo y accesibilidad que guie por la ciudad hacia la intervención de estos lugares, buscado su rehabilitación, mantenimiento, y conservación.

Conocer los resultados de decálogo de espacios públicos peatonales en el lugar.

Conocer los resultados de iniciativa de espacios públicos peatonales con los ciudadanos y las entidades públicas - privadas.

\section{BIBLIOGRAFÍA}

BORJA, JORDI. Espacio público y derecho de la ciudad. Barcelona, España (2003).

BORJA, JORDI. Luces y sombras del urbanismo de Barcelona. Universitat oberta de Catalunya. (2010). Barcelona, España.

HARVEY, DAVID. Ciudades rebeldes. Del derecho de la ciudad a la revolución urbana. (2013). Madrid. España.

LEFEBVRE, HENRI. El derecho a la ciudad. (1978). Barcelona. España.

CORBUSIER, LE. C\& SERT, J. L. (1937). Cas d'application: villes. Rapport no. 2, V Congrès de Paris, 1937“"Logis et loisirs”, editado por Ungers\&Ungers, Documents of Modern Architecture. 23 (traducción libre).

GEHL, JAN. Ciudades para la gente. (2014). Buenos Aires, Argentina.

GEHL, J. (1971): "Life between buildings. Using Public Space" $1^{\text {a }}$ Edicion. Arkitektens Forlag. The Danish Architectural Press. Copenhagen.

ROVIRA, ENRIQUE. El libro blanco de la accesibilidad. (2003). Barcelona, España. 
CAÑON, LUIS. 2010. Transport and Social Exclusion in Medellin. Potential, Opportunities and Challenges. Londres: Development Planning Unit, University College London.

NACIONES UNIDAS ONU. Carta Mundial de Derecho a la ciudad. Barcelona (2005).

BALLÉN DUQUE, FRIDOLE. Derecho a la movilidad. La experiencia de Bogotá, D.C. Comisión Nacional del Servicio Civil. Bogotá D.C.

CARERI, FRANCESCO. Walkscapes: El andar como práctica estética. (2013).

Documentos técnicos.

PRADA, LUIS ESTEBAN. "Guía práctica de la movilidad peatonal urbana". Una cartilla para todos los peatones. (2006). Bogotá. D.C.

INSTITUTO DE DESARROLLO URBANO Y SECRETARIA DISTRITAL DE PLANEACIÓN (TALLER DE ESPACIO PÚBLICO). Cartilla de andenes. Actualizado (17 de Diciembre de 2015). Bogotá. D.C.

HUERTA, JAIME. Discapacidad y diseño accesible. Diseño urbano y arquitectónico para personas con discapacidad. (2007). Lima, Perú.

MONROY FLORES, ELVIRA VEREL. Planeación humanizante y derecho a la ciudad para personas en situación de discapacidad. (2011). Universidad La Gran Colombia. Bogotá. D.C.

INSTITUTE FOR TRANSPORTATION AND DEVELOPMENT POLICY (ITDP). Transit-oriented Development (TOD) (2013). Mexico. D.F.

FERNANDEZ BERMEJO, MARIA EULALIA. La ciudad accesible, Revista científica sobre accesibilidad universal. (2014). Madrid, España.

MOLINA LOPEZ, LUIS. La cartografía social y su aplicación a la planificación municipal y regional. Grupo de estudios urbano regionales del Magdalena medio Unipaz. (Septiembre de 2005). Villavicencio. Colombia.

NACIONES UNIDAS ONU, La carta mundial por el Derecho a la ciudad. (Septiembre de 2005). Barcelona, España.

NACIONES UNIDAS ONU. Normas Uniformes sobre la igualdad de oportunidades para las personas con discapacidad. Asamblea General. (1996).

ORGANIZACIONES DE LOS ESTADOS AMERICANOS, Convención Interamericana para la eliminación de todas las formas de discriminación contra las personas con discapacidad. (7 de junio de 1999). Ciudad de Guatemala, Guatemala.

ASAMBLEA GENERAL DE LAS NACIONES UNIDAS. Declaración Universal de los Derechos humanos.(10 de diciembre de 1948). New york.

CONGRESO DE COLOMBIA, LEY 1618 DE 2013. Por el medio de la cual se establecen las disposiciones para garantizar el pleno ejercicio de los derechos de las personas con discapacidad. (27 de febrero de 2013). Bogotá. D.C.

LA ASAMBLEA DE LAS NACIONES UNIDAS ONU. La nueva agenda urbana. (23 de diciembre de 2016).

ALCALDÌA MAYOR DE BOGOTÁ. Decreto 561 de 2015. Por el medio se actualiza la cartilla de andenes adoptada mediante el Decreto Distrital 1003 de 2000, adicionada mediante el Decreto Distrital 379 de 2002 y actualizada mediante el Decreto distrital 602 de 2007, y se dictan otras disposiciones. (21 de Diciembre de 2015).

\section{Fuentes electrónicas:}

http://www.alcaldiabogota.gov.co/sisjur/normas/Norma1.jsp?i=27092 (Consulta: Marzo/ 2016).

https://www.dnp.gov.co/programas/desarrollo-social/pol\%C3\%ADticas-sociales-

transversales/Paginas/discapacidad.aspx (Consulta: Agosto/2016). 
http://www.bdigital.unal.edu.co/3794/ (Consulta: Septiembre7 2016).

http://www.vienaeditorial.com/barcelonaaccesible/ (Consulta: Septiembre/ 2016).

http://nelidabarbeito.blogspot.com.co/2016/04/barcelona-accesibilidad-en-urbanismo.html (Consulta: Septiembre/ 2016).

http://www.accesibilidadglobal.com/2014/09/la-ciudad-accesible-vs-la-ciudad.html (Consulta: Mayo 2016).

http://www.edu.gov.co/index.php/inicio/118-lo-ultimo/615-gestionsocialuva.html (Consulta: Octubre/ 2016).

http://www.un.org/spanish/disabilities/default.asp?id=498. (Consulta: 30/04/2017)

http://www.un.org/spanish/disabilities/default.asp?id=574

Antonio Corbalán Pinar, la ciudad accesible Vs Ciudad ortésica. (1 de septiembre de 2014).

Fundación Alejandra Forlán Lanza campaña de accesibilidad, (Agosto 7 de 2012) www.elobservador.com.uy/fundacion-alejandra-forlan-lanza-campana-accesibilidad-n229802

Organización de las Naciones Unidas ONU, Carta Mundial por el derecho a la ciudad. Septiembre 2005. http://www.hic-al.org/documentos/cartaderechociudad.pdf (Consulta: 25/04/2017)

Cañon, L., 2010. Transport and Social Exclusion in Medellin. Potential, Opportunities and Challenges.

Londres: Development Planning Unit, University College London

Guía práctica de la movilidad peatonal urbana. Una cartilla para todos los peatones. (pág. 15) 